\begin{tabular}{|c|c|}
\hline Citation & $\begin{array}{l}\text { Langouche L, Lehmhul I, Vander Perre S, Koehrle J, Van den Berghe G } \\
\text { (2016) } \\
\text { Circulating 3-T1AM and 3,5-T2 in critically ill patients: a cross-sectional } \\
\text { observational study } \\
\text { Thyroid } 2016 \text { Sep } 17 \text { [Epub ahead of print]. }\end{array}$ \\
\hline Archived version & $\begin{array}{l}\text { Author manuscript: the content is identical to the content of the published } \\
\text { paper, but without the final typesetting by the publisher }\end{array}$ \\
\hline Published version & doi: $10.1089 /$ thy .2016 .0214 \\
\hline Journal homepage & http://online.liebertpub.com/thy \\
\hline Author contact & lies.langouche@kuleuven.be \\
\hline & Klik hier als u tekst wilt invoeren. \\
\hline IR & https://lirias.kuleuven.be/handle/123456789/551508 \\
\hline
\end{tabular}

(article begins on next page) 


\section{Circulating 3-T1AM and 3,5-T2 in critically ill patients: a cross-sectional observational study \\ Lies Langouche $\mathrm{PhD}^{1 *}$, Ina Lehmphul $\mathrm{PhD}^{2^{*}}$, Sarah Vander Perre $\mathrm{MSc}^{1}$, Josef Köhrle PhD², Greet Van den Berghe MD PhD' ${ }^{1}$}

${ }^{1}$ Clinical Division and Laboratory of Intensive Care Medicine, Department of Cellular and Molecular Medicine, KU Leuven, Leuven, Belgium, ${ }^{2}$ Institut für Experimentelle Endokrinologie, Charité-Universitätsmedizin Berlin, Germany

*These authors contributed equally to this manuscript

Email addresses: Lies.Langouche@kuleuven.be; Ina.Lehmphul@charite.de; Sarah.VanderPerre@kuleuven.be; Josef.Koehrle@charite.de; Greet.VandenBerghe@kuleuven.be

Abbreviated title: 3-T1AM and 3,5-T2 in critically ill patients

Key words: critical illness, NTI, sepsis, thyroid hormones, metabolites 


\begin{abstract}
Background: Critical illness is hallmarked by low circulating T4 and T3 concentrations, in the presence of elevated rT3 and low-normal TSH, referred to as non-thyroidal illness (NTI). Thyroid hormone (TH) metabolism is substantially increased during NTI, in part explained by enhanced deiodinase 3 (D3) activity. T4- and T3-sulfate concentrations are elevated, due to suppressed D1 activity in the presence of unaltered sulfotransferase activity, and 3,3'-diiodothyronine (3,3'-T2) concentrations are normal. To further elucidate the driving forces behind increased TH metabolism during NTI, two other potential T4 metabolites, 3,5-diiodothyronine (3,5-T2) and 3iodothyronamine (3-T1AM), were measured and related to their potential TH precursors.
\end{abstract}

Methods: Morning blood samples were collected cross-sectionally from 83 critically ill patients on a University Hospital ICU and from 38 demographically matched healthy volunteers. Serum TH and binding proteins were quantified with commercial assays, 3,5-T2 and 3-T1AM with in-house developed immunoassays.

Results: Critically ill patients revealed, besides the NTI, a median 44\% lower serum 3-T1AM concentration $(p<0.0001)$ and a $30 \%$ higher serum 3,5-T2 concentrations $(p=0.01)$ than healthy volunteers. Non-survivors and patients diagnosed with sepsis upon ICU admission had significantly higher 3,5-T2 ( $p \leq 0.01)$ but comparable 3T1AM ( $p>0.2$ ) concentrations than other patients. Multivariable linear regression analysis adjusted for potential precursors revealed that the reduced serum 3-T1AM was positively correlated with the low serum T3 $(p<0.001)$ but unrelated to serum T4 or rT3. The elevated 3,5-T2 concentration did not independently correlate with $\mathrm{TH}$.

Conclusions: Increased TH metabolism during NTI could not be explained by increased conversion to 3-T1AM, as circulating 3-T1AM was suppressed in proportion to the concomitantly low T3 concentrations. Increased conversion of T4 and/or T3 to 3,5-T2 could be possible, as serum 3,5-T2 concentrations were elevated. Whether 3-T1AM or 3,5-T2 play a functional role during critical illness needs further investigation. 


\section{Introduction}

Critically ill patients suffering from trauma, complications after surgery, or from severe illnesses such as sepsis develop the nonthyroidal illness syndrome (NTI), typically characterized by low circulating $\mathrm{T} 4$ and $\mathrm{T} 3$, in the presence of low-normal TSH (1-4). The observed low circulating T4 and T3 levels are partly explained by alterations in peripheral thyroid hormone (TH) metabolism. Outer-ring deiodination is reduced and inner-ring deiodination is increased, together lowering circulating T3 and increasing inactive reverse T3 (rT3) (5-7). Experimental animal models and analyses in human liver biopsies have suggested that the expression and the activity of type-3 deiodinase (D3), the enzyme mediating the conversion of T4 to rT3, is upregulated and expression and activity of D1, the enzyme that converts T4 to T3, is suppressed (7-9). Also, overall thyroid hormone metabolism is substantially increased in NTI of critical illness, as a substitution dose of T4 and/or T3 is unable to normalize plasma thyroid hormone concentrations during critical illness in patients (10-12). In critically ill animals that received a substitution dose of T4, circulating T4 was even further reduced, without a concomitant change in T3, rT3, or 3,3'-T2 (13). Patients suffering from NTI also display low to normal 3,3'-T2 concentrations (14-16). Together the available data suggest that increased TH breakdown during critical illness may be due to conversion or conjugation of T4 to other metabolites.

Sulfation of $\mathrm{T} 4$ and $\mathrm{T} 3$ is one such alternative pathway. However, although we and others have previously documented elevated levels of T4-S and T3-S in critically ill patients, these were predominantly attributed to suppressed D1 enzyme activity in critically ill patients $(13,17,18)$. While activity of D1 is decreased, which exclusively and rapidly deiodinates iodothyronine sulfates, sulfotransferase enzyme activity and expression were not increased during critical illness $(13,18)$.

Thyronamines are a relatively novel class of potential T4 metabolites of which 3-T1AM has been detected in vivo $(19,20)$. High doses of 3-T1AM can evoke hypothermia and bradycardia $(19,20)$. The biosynthesis pathways of 3-T1AM are not completely clarified, although in vitro thyronamines are isozymespecific substrates for deiodinases and intestinal decarboxylation of TH by ornithine decarboxylase has been observed $(21,22)$. Athyreotic patients on L-T4 replacement therapy also had higher serum 3-T1AM concentrations than individuals with intact thyroid indicating its extrathyroidal formation from supplemented L-T4 (23). The TH metabolite 3,5-T2, which is theoretically formed through D1 deiodination of T3, has long been 
considered as a physiological inactive and minor metabolite of $\mathrm{T} 4$ and $\mathrm{T} 3$, but recent studies indicate that this metabolite might have a physiological impact on energy metabolism (24-28).

To further elucidate the driving forces behind increased TH metabolism during the NTI of critical illness, we investigated the impact of critical illness on these two potential T4 metabolites 3,5-T2 and 3-T1AM and their association with potential precursor TH. In a cross-sectional observational study, we collected morning blood samples of 83 surgical ICU patients and 38 demographically matched healthy control individuals to quantify serum concentrations of total T4 (TT4), total T3 (TT3), rT3, and 3,5-T2 and 3-T1AM. Because free hormone levels could not be determined accurately as patient samples were collected through heparinized arterial lines, we quantified thyroxine binding globulin (TBG) and Apolipoprotein B, the primary carrier of 3-T1AM in the circulation $(29,30)$. 


\section{Material and Methods}

\section{Patients}

On 5 consecutive collection days (with 5 days between each collection), morning blood samples were taken from all patients who were admitted to the surgical ICU and for whom informed consent was given by the patient or the next of kin. Those patients who were still in the ICU on more than 1 collection day, were only included once in the study. Undiluted blood samples were collected at 6 am via an arterial catheter in place for clinical purposes. After sampling and centrifugation, serum was kept frozen at $-80^{\circ} \mathrm{C}$ until batched analysis. As

healthy references, we collected morning blood samples by venipuncture from 38 overnight-fasted healthy volunteers with comparable demographics as the patient population (Table 1). The study protocol and consent forms were approved by the Institutional Ethical Review Board (approval number ML2112 and ML4190).

\section{Quantification of circulating hormones, metabolites and binding proteins}

The serum concentrations of the metabolites 3-T1AM $(23)$ and 3,5-T2 $(28,31)$ were quantified with in house developed monoclonal-antibody based chemiluminescence immunoassays, partly adapted from previously described. For the 3-T1-AM assay, plates were now coated with 3-T1AM-labelled BSA (50 $\mu \mathrm{g}$ in $0.1 \mathrm{ml}$ per well; overnight at $\left.4^{\circ} \mathrm{C}\right)$, instead of coating with a polyclonal rabbit anti-mouse IgG $(H \& L)$ as capture antibody, to minimize cross-reactivities between antibodies. The same previously used (23) monoclonal antibody (mAb) for 3T1AM was now biotinylated ( $10 \mathrm{ng}$ in $0.05 \mathrm{ml}$ per well). Incubation time (1.5h at $750 \mathrm{rpm}$ ) and serum volume (25 $\mu l$ per determination) remained unchanged. The detection system consisted of streptavidin-labelled Europium, binding to the biotin-label and producing a stable fluorescence signal for quantification. The modified 3-T1AM assay is now characterized by a limit of detection below $1 \mathrm{nM}(0.93 \mathrm{nM})$. 3-T1AM values were calculated from a log-transformed standard calibrator curve $\left(0.5-50 \mathrm{nM}, \mathrm{R}^{2}=0.99\right)$ in artificial serum matrix composed of $7 \% \mathrm{BSA}$ (w/v) in $10 \mathrm{mM}$ phosphate-buffered salt solution, $\mathrm{pH} 7.2$, containing $0.02 \%$ Tween 20 (Supplemental figure 1). Intra- and interassay coefficients of variation were less than $13 \%$. The 3,5-T2 values were calculated from a logtransformed standard curve of 0.05 to $10 \mathrm{nM}$ as published $(28,31)$. The limit of quantification of the 3,5-T2-assay was $0.2 \mathrm{nM}$, the limit of detection was $0.05 \mathrm{nM}$. Because $25 \%$ of the samples were below $0.2 \mathrm{nM}$, the statistical analysis was redone by replacing these values with the limit of quantification cut-off value of $0.2 \mathrm{nM}$. As this had 
no effect on the statistical outcome, the limit of detection cut-off was used. Serum TSH was measured with a commercially available immunoradiometeric assay and total $\mathrm{T} 4$ and total $\mathrm{T} 3$ were determined with commercial radioimmunassays, all from Beckman Coulter (Immunotech, Czech Republic). As blood samples of ICU patients were always taken via heparinized lines, free hormone concentrations were not determined because these would give artefactuous results (32). We used a commercially available radioimmunoassay to quantify serum rT3 concentrations (ZenTech, Angleur, Belgium). Serum TBG was quantified by a commercial sandwich ELISA (LifeSpan Biosciences, Seattle WA). Apolipoprotein B (ApoB) was also quantified by a commercial ELISA (RnDSystems, Minneapolis, MN).

\section{Statistical analysis}

Parametrical Student's t-tests and non-parametrical Mann-Whitney $U$ tests were used to analyze differences between control subjects and ICU patients, as appropriate for normally and non-normally distributed data, respectively. Non-normally distributed data were analyzed with parametric tests if after log- or (double) square root-transformation this resulted in a near-normal distribution. With univariable and multivariable linear regression analyses, the presence of an independent association between serum 3-T1AM, 3,5-T2 and their respective potential precursors was assessed. The presence of multicollinearity among the regressor variables of the multivariable regression analyses was excluded using the tolerance, variance inflation factor, condition indices, and variance proportions (33). All statistical analyses were performed with JMP12 for Windows (SAS Institute Inc.). Statistical significance was set at a two tailed p-value at or below 0.05 . 


\section{Results \\ Circulating thyroid hormones, metabolites and binding proteins}

Healthy control subjects and ICU patients had comparable demographic characteristics (Table 1). Samples were collected from a diverse group of surgical ICU patients after a variable time spent in the ICU (Table 1). All ICU patients demonstrated serum TT3 concentrations below that of the healthy controls (Figure 1C). The mean serum TT4 concentration was also lower in the ICU patients in the presence of low mean serum TSH (Figure 1A-B). In contrast, the mean rT3 serum concentration was significantly higher in ICU patients compared to healthy controls (Figure 1D).

The serum concentrations of the metabolite 3-T1AM were significantly lower in ICU patients than in healthy control subjects (Figure 2A). In contrast, the serum concentrations of 3,5-T2 were significantly higher in ICU patients than in healthy controls (Figure 2B). Furthermore, patients who eventually did not survive their ICU stay displayed higher serum 3,5-T2 concentrations than ICU survivors (Figure 2D), whereas surviving and nonsurviving ICU patients had comparable 3-T1AM concentrations (Figure 2C). Also patients diagnosed with sepsis upon admission had higher serum 3,5-T2 $(p=0.006)$ than patients who did not have a sepsis diagnosis on admission, but comparable serum 3-T1AM concentrations $(p=0.6)$.

The serum TBG concentration was significantly lower in ICU patients than in healthy controls (Figure 3A). Because serum 3-T1AM predominantly resides in ApoB100 containing low-density lipoproteins (29), we also quantified the serum ApoB concentration, which was comparable in healthy control subjects and ICU patients (Figure 3B).

\section{Univariable and multivariable regression analysis}

To assess the relationship between the two novel metabolites and potential TH precursors, we first performed univariable regression analyses. In univariable analysis, 3-T1AM was significantly positively correlated with T4 and T3 and negatively with rT3 and 3,5-T2 (Table 2). In univaribale analysis, the metabolite 3,5-T2 was negatively, albeit weakly, correlated with its putative precursors T4 and T3 (Table 3). Because the concentrations 
of these hormones are related to each other, we also performed a multivariable regression analysis adjusting for the studied potential precursor hormones. This analysis indicated that only total T3 was independently and positively correlated with 3-T1AM (for each nmol/l increase of TT3, 3-T1AM had an estimated increase of 2.22 nmol/l, $\mathrm{p}=0.001$; Table 2). The weak association between $\mathrm{T} 3$ or $\mathrm{T} 4$ and 3,5-T2 was no longer present in the multivariable regression analysis adjusted for all studied precursor TH (Table 3). 


\begin{abstract}
Discussion
In this cross-sectional observational study, we demonstrate that critically ill patients with NTI have a median 44\% lower serum 3-T1AM concentration, in proportion to the concomitantly low T3 concentrations, and a median 30\% higher serum 3,5-T2 concentrations than matched healthy control subjects. Enhanced TH metabolism during NTI could thus not be explained by an increased conversion to 3-T1AM. Increased deiodination of T4 and/or T3 to 3,5-T2 could contribute to the high TH turnover during NTI of critical illness.
\end{abstract}

We hypothesized that during critical illness T4 is not only metabolized to rT3, but that also other metabolites might be increased during critical illness $(13,16)$. This hypothesis was based on previous findings in critically ill patients and animals, where T4 substitution could not normalize T4, nor T3, and this without a concomitant change in T3, rT3, or 3,3'-T2 (10-13). Two potential metabolites with physiological activities, 3,5-T2 and 3-T1AM, were therefore investigated.

We observed a median $30 \%$ increased 3,5-T2 concentration in critically ill patients, particularly in patients with an unfavorable outcome. Also in cardiac surgery patients, patients with sepsis, liver cirrhosis and brain tumors with NTI, 3,5-T2 concentrations have been reported to be elevated $(31,34)$. Thus, during critical illness, part of T4 and T3 might indeed be metabolized to 3,5-T2. In theory, D1 could catalyze the conversion from T4 to T3 to 3,5-T2. However, regression analysis indicated only a weak univariable association between both T3 and T4 and 3,5-T2. Furthermore, hepatic D1 activity is reduced in critically ill patients (7). However, clear evidence on which deiodinases are involved in the formation and further metabolism of 3,5-T2 is currently lacking. It is possible that D2, which was previously reported to be upregulated in muscle of prolonged critically ill patients, might also be involved (35). In addition to an increased conversion of T3 and/or T4 to 3,5-T2, a decrease in 3,5T2 metabolism or a decreased tissue uptake might also (partly) explain the increase in circulating 3,5-T2. Which pathways, compartments or organs might be involved in the generation and metabolism of 3,5-T2 and whether 3,5-T2 plays a functional role during critical illness is beyond the scope of this observational study, but needs further investigation.

In contrast with 3,5-T2, we observed a median 40\% lower serum 3-T1AM concentration in critically ill patients as compared with healthy controls. It thus seems unlikely that an increased decarboxylation of T4 or T3 
plays a role in the development of $\mathrm{NTI}$ or in the elevated $\mathrm{TH}$ turnover. The concentration of 3-T1AM independently correlated with serum T3 only, which suggests that its decreased concentration is likely due to a decreased availability of T3 as precursor. A univariate correlation between 3T1-AM and T3 was also observed in a mixed population of patients suffering from cardiac or thyroid disease (36), whereas no correlation to T3 was observed in 2 smaller observational studies in cardiac surgery patients with NTI (31), or patients on T4 substitution (23). Decreased conversion of 3,5-T2 to 3-T1AM might theoretically also have played a role, suggested by the (univariate) negative correlation of both metabolites. Indeed, in vitro conversion from 3,5-T2 to 3-T1AM has been demonstrated earlier (22). However, 3-T1AM is also a substrate for D3, and could thus have been further deiodinated (21). Furthermore, although the biosynthesis pathways of 3-T1AM are not completely clear, intestinal decarboxylation by ornithine decarboxylase and deiodination has been observed (22), and intestinal activity of ornithine decarboxylase is increased in septic animals (37). Thus, a tissue specific increase in 3-T1AM, not reflected in the circulating levels, cannot be excluded. Alternatively, oxidative deamination of 3T1AM might be an alternative pathway involved in bringing about low T3 and low 3-T1AM, which warrants further investigation (38). Also conjugation of 3-T1AM to sulfates has been reported in vitro (39). Whether altered enterohepatic recycling of TH in critical illness contributes to these inverse changes in 3,5-T2 and 3-T1AM serum concentrations remains to be clarified.

The largest part of circulating T4 and T3 is bound to carrier proteins, of which TBG is the dominant binding protein (40). The observed decreased serum TBG concentration, but also decreased serum albumin, commonly found in critically ill patients, might have increased the amount of circulating free 3,5-T2, but its binding to serum TH distributor proteins is not well characterized. Different from circulating T3 and T4, 3-T1AM resides predominantly in the ApoB100 containing low-density lipoprotein fraction which also can affect its intracellular uptake (29). As the serum ApoB concentration in patients was comparable to that of healthy controls, an effect on 3-T1AM bioavailability during critical illness or decreased (free) serum concentrations are less likely. Because 3T1AM is largely bound to the carrier protein ApoB100 (29), we speculate that this might also have played a role in the much lower 3-T1AM concentrations found with mass-spectrometry (36) compared to the values we quantified with our immunoassay in sera of healthy controls. For the LC-MS/MS analysis, serum samples were deproteinized and lipid depleted, which might have removed the largest part of bound 3-T1AM from the sample 
(36). This would suggest that the LC-MS/MS method would represent the "free/non-bound 3-T1AM fraction", whereas the immunoassay might have detected the (nearly) total 3-T1AM fraction in human serum. Of course, the ratio and concentration of the reported TH metabolites in serum might not adequately reflect steady-state concentrations in the tissues. Indeed, 3-T1AM appears to accumulate in peripheral tissues such as liver, heart, kidney and muscle, at much higher levels than in circulation, but also 3,5-T2 has been reported to accumulate in mouse liver after exogenous administration $(41,42)$.

In conclusion, critically ill patients not only suffer from low T4 and T3, but also 3-T1AM is decreased. On the contrary, in addition to the increased conversion of T4 to rT3, also enhanced metabolism to 3,5-T2 might play a role in the development of NTI. Whether 3-T1AM or 3,5-T2 play a functional role during critical illness or contribute to its manifestation, needs further investigation.

\section{Acknowledgements}

We thank the volunteers, the patients and their family members for participating in this study. GVdB, via the University of Leuven (KU Leuven), receives long-term structural research support from the Methusalem Program funded by the Flemish Government (METH/08/07 and METH/14/06) and holds a European Research Council Advanced Grant AdvG-2012-321670 from the Ideas Program of the European Union seventh framework program. JK and IL are supported by research grants from the Priority Programme 1629 ThyroidTransAct (KO 922/16-2 and 922/17-1/2) funded by the Deutsche Forschungsgemeinschaft DFG and grants from the ChariteUniversitätsmedizin Berlin.

\section{Disclosure statement:}

The authors have declared that no conflict of interest exists 


\section{Corresponding author:}

Lies Langouche, Laboratory of Intensive Care Medicine, KU Leuven, Herestraat 49 bus 503, B-3000 Leuven.

Email: lies.langouche@.kuleuven.be Phone: +32 16330524. 


\section{References}

1. Grill E, Strong M, Sonnad SS, Sarani B, Pascual J, Collins H, et al. Altered thyroid function in severely injured patients. J Surg Res. 2013;179(1):132-7.

2. Leon-Sanz M, Lorente JA, Larrodera L, Ros $P$, Alvarez J, Esteban AE, et al. Pituitary-thyroid function in patients with septic shock and its relation with outcome. Eur J Med Res. 1997;2(11):477-82.

3. Boelen A, Schiphorst MC, Wiersinga WM. Relationship between serum 3,5,3'-triiodothyronine and serum interleukin-8, interleukin-10 or interferon gamma in patients with nonthyroidal illness. J Endocrinol Invest. 1996;19(7):480-3.

4. Kaplan MM, Larsen PR, Crantz FR, Dzau VJ, Rossing TH, Haddow JE. Prevalence of abnormal thyroid function test results in patients with acute medical illnesses. Am J Med. 1982;72(1):9-16.

5. Debaveye Y, Ellger B, Mebis L, Darras VM, Van den Berghe G. Regulation of tissue iodothyronine deiodinase activity in a model of prolonged critical illness. Thyroid. 2008;18(5):551-60.

6. Mebis L, Van den Berghe G. Thyroid axis function and dysfunction in critical illness. Best Pract Res Clin Endocrinol Metab. 2011;25(5):745-57.

7. Peeters RP, Wouters PJ, Kaptein E, van Toor H, Visser TJ, Van den Berghe G. Reduced activation and increased inactivation of thyroid hormone in tissues of critically ill patients. J Clin Endocrinol Metab. 2003;88(7):3202-11.

8. Rodriguez-Perez A, Palos-Paz F, Kaptein E, Visser TJ, Dominguez-Gerpe L, varez-Escudero J, et al. Identification of molecular mechanisms related to nonthyroidal illness syndrome in skeletal muscle and adipose tissue from patients with septic shock. Clin Endocrinol (Oxf). 2008;68(5):821-7.

9. Peeters RP, van der GS, Wouters PJ, Darras VM, van Toor H, Kaptein E, et al. Tissue thyroid hormone levels in critical illness. J Clin Endocrinol Metab. 2005;90(12):6498-507.

10. Kaptein EM, Sanchez A, Beale E, Chan LS. Clinical review: Thyroid hormone therapy for postoperative nonthyroidal illnesses: a systematic review and synthesis. J Clin Endocrinol Metab. 2010;95(10):4526-34.

11. Brent GA, Hershman JM. Thyroxine therapy in patients with severe nonthyroidal illnesses and low serum thyroxine concentration. J Clin Endocrinol Metab. 1986;63(1):1-8.

12. Becker RA, Vaughan GM, Ziegler MG, Seraile LG, Goldfarb IW, Mansour EH, et al. Hypermetabolic low triiodothyronine syndrome of burn injury. Crit Care Med. 1982;10(12):870-5.

13. Debaveye Y, Ellger B, Mebis L, Visser TJ, Darras VM, Van den Berghe G. Effects of substitution and highdose thyroid hormone therapy on deiodination, sulfoconjugation, and tissue thyroid hormone levels in prolonged critically ill rabbits. Endocrinology. 2008;149(8):4218-28.

14. Pinna G, Hiedra L, Meinhold H, Eravci M, Prengel H, Brodel O, et al. 3,3'-Diiodothyronine concentrations in the sera of patients with nonthyroidal illnesses and brain tumors and of healthy subjects during acute stress. $J$ Clin Endocrinol Metab. 1998;83(9):3071-7.

15. Faber J, Kirkegaard C, Lumholtz IB, Siersbaek-Nielsen K, Friis T. Measurements of serum 3',5'diiodothyronine and 3,3'-diiodothyronine concentrations in normal subjects and in patients with thyroid and nonthyroid disease: studies of 3',5'-diiodothyronine metabolism. J Clin Endocrinol Metab. 1979;48(4):611-7.

16. Jonklaas J, Sathasivam A, Wang H, Finigan D, Soldin OP, Burman KD, et al. 3,3'-diiodothyronine concentrations in hospitalized or thyroidectomized patients: results from a pilot study. Endocr Pract. 2014;20(8):797-807.

17. Chopra IJ, Wu SY, Teco GN, Santini F. A radioimmunoassay for measurement of 3,5,3'-triiodothyronine sulfate: studies in thyroidal and nonthyroidal diseases, pregnancy, and neonatal life. J Clin Endocrinol Metab. 1992;75(1):189-94.

18. Peeters RP, Kester MH, Wouters PJ, Kaptein E, van Toor H, Visser TJ, et al. Increased thyroxine sulfate levels in critically ill patients as a result of a decreased hepatic type I deiodinase activity. J Clin Endocrinol Metab. 2005;90(12):6460-5. 
19. Scanlan TS, Suchland KL, Hart ME, Chiellini G, Huang Y, Kruzich PJ, et al. 3-lodothyronamine is an endogenous and rapid-acting derivative of thyroid hormone. Nat Med. 2004;10(6):638-42.

20. Piehl S, Hoefig CS, Scanlan TS, Kohrle J. Thyronamines--past, present, and future. Endocr Rev. 2011;32(1):64-80.

21. Piehl S, Heberer T, Balizs G, Scanlan TS, Smits R, Koksch B, et al. Thyronamines are isozyme-specific substrates of deiodinases. Endocrinology. 2008;149(6):3037-45.

22. Hoefig CS, Wuensch T, Rijntjes E, Lehmphul I, Daniel H, Schweizer U, et al. Biosynthesis of 3iodothyronamine from L-thyroxine in murine intestinal tissue. Endocrinology. 2015:en20141499.

23. Hoefig CS, Kohrle J, Brabant G, Dixit K, Yap B, Strasburger CJ, et al. Evidence for extrathyroidal formation of 3-iodothyronamine in humans as provided by a novel monoclonal antibody-based chemiluminescent serum immunoassay. J Clin Endocrinol Metab. 2011;96(6):1864-72.

24. Faber J, Faber OK, Lund B, Kirkegaard C, Wahren J. Hepatic extraction and renal production of 3,3'diiodothyronine and 3',5'-diiodothyronine in man. J Clin Invest. 1980;66(5):941-5.

25. Moreno M, de LP, Lombardi A, Silvestri E, Lanni A, Goglia F. Metabolic effects of thyroid hormone derivatives. Thyroid. 2008;18(2):239-53.

26. Lombardi A, Moreno M, de LP, lossa S, Busiello RA, Goglia F. Regulation of skeletal muscle mitochondrial activity by thyroid hormones: focus on the "old" triiodothyronine and the "emerging" 3,5-diiodothyronine. Front Physiol. 2015;6:237.

27. Pietzner M, Lehmphul I, Friedrich N, Schurmann C, Ittermann T, Dorr M, et al. Translating pharmacological findings from hypothyroid rodents to euthyroid humans: is there a functional role of endogenous 3,5-T2? Thyroid. 2015;25(2):188-97.

28. Lehmphul I, Brabant G, Wallaschofski H, Ruchala M, Strasburger CJ, Kohrle J, et al. Detection of 3,5diiodothyronine in sera of patients with altered thyroid status using a new monoclonal antibody-based chemiluminescence immunoassay. Thyroid. 2014;24(9):1350-60.

29. Roy G, Placzek E, Scanlan TS. ApoB-100-containing lipoproteins are major carriers of 3-iodothyronamine in circulation. J Biol Chem. 2012;287(3):1790-800.

30. Schussler GC. The thyroxine-binding proteins. Thyroid. 2000;10(2):141-9.

31. Dietrich JW, Muller P, Schiedat F, Schlomicher M, Strauch J, Chatzitomaris A, et al. Nonthyroidal Illness Syndrome in Cardiac Illness Involves Elevated Concentrations of 3,5-Diiodothyronine and Correlates with Atrial Remodeling. Eur Thyroid J. 2015;4(2):129-37.

32. Stockigt JR, Lim CF. Medications that distort in vitro tests of thyroid function, with particular reference to estimates of serum free thyroxine. Best Pract Res Clin Endocrinol Metab. 2009;23(6):753-67.

33. Midi H, Sarkar SK, Rana S. Collinearity diagnostics of binary logistics regression model. Journal of Interdisciplinary Mathematics. 2010(13):253-67.

34. Pinna G, Meinhold H, Hiedra L, Thoma R, Hoell T, Graf KJ, et al. Elevated 3,5-diiodothyronine concentrations in the sera of patients with nonthyroidal illnesses and brain tumors. J Clin Endocrinol Metab. 1997;82(5):153542.

35. Mebis L, Paletta D, Debaveye $Y$, Ellger B, Langouche L, D'Hoore A, et al. Expression of thyroid hormone transporters during critical illness. Eur J Endocrinol. 2009;161(2):243-50.

36. Galli E, Marchini M, Saba A, Berti S, Tonacchera M, Vitti P, et al. Detection of 3-iodothyronamine in human patients: a preliminary study. J Clin Endocrinol Metab. 2012;97(1):E69-74.

37. Noguchi Y, Meyer TA, Tiao G, Ogle CK, Fischer JE, Hasselgren PO. Influence of sepsis and endotoxemia on polyamine metabolism in mucosa of small intestine in rats. Metabolism. 1996;45(1):28-33.

38. Wood WJ, Geraci T, Nilsen A, DeBarber AE, Scanlan TS. lodothyronamines are oxidatively deaminated to iodothyroacetic acids in vivo. Chembiochem. 2009;10(2):361-5. 
39. Pietsch CA, Scanlan TS, Anderson RJ. Thyronamines are substrates for human liver sulfotransferases. Endocrinology. 2007;148(4):1921-7.

40. Oppenheimer JH. Role of plasma proteins in the binding, distribution and metabolism of the thyroid hormones. N Engl J Med. 1968;278(21):1153-62.

41. Saba A, Chiellini G, Frascarelli S, Marchini M, Ghelardoni S, Raffaelli A, et al. Tissue distribution and cardiac metabolism of 3-iodothyronamine. Endocrinology. 2010;151(10):5063-73.

42. Jonas W, Lietzow J, Wohlgemuth F, Hoefig CS, Wiedmer P, Schweizer U, et al. 3,5-Diiodo-L-thyronine (3,5t2) exerts thyromimetic effects on hypothalamus-pituitary-thyroid axis, body composition, and energy metabolism in male diet-induced obese mice. Endocrinology. 2015;156(1):389-99.

43. Knaus WA, Draper EA, Wagner DP, Zimmerman JE. APACHE II: a severity of disease classification system. Crit Care Med. 1985;13(10):818-29. 
Tables

Table 1: Baseline characteristics and ICU outcome

\begin{tabular}{|c|c|c|c|}
\hline & $\begin{array}{l}\text { Healthy Control } \\
\text { Subjects } \\
(n=38)\end{array}$ & $\begin{array}{c}\text { ICU } \\
\text { Patients } \\
(n=83)\end{array}$ & P-value \\
\hline Age, yr. - mean $\pm S E$ & $63.5 \pm 1.0$ & $64.7 \pm 1.5$ & 0.5 \\
\hline Sex, - n. (\%) male & $20(53)$ & $54(65)$ & 0.2 \\
\hline $\mathrm{BMl}, \mathrm{kg} / \mathrm{m}^{2}$ - mean $\pm \mathrm{SE}$ & $25.5 \pm 0.6$ & $26.4 \pm 0.5$ & 0.3 \\
\hline Days in ICU at day of sample - median [IQR] & & $3[1-6]$ & \\
\hline $\begin{array}{l}\text { Diagnostic category at ICU admission - n. (\%) } \\
\text { Cardiac surgery } \\
\text { Complicated surgery }{ }^{1} \\
\text { Transplantation } \\
\text { Trauma, burns or reconstructive surgery } \\
\text { Other }\end{array}$ & - & $\begin{array}{c}44(53) \\
16(19) \\
8(10) \\
8(10) \\
7(8)\end{array}$ & \\
\hline APACHE II score - mean \pm SE & - & $26 \pm 1$ & \\
\hline Diagnosis of sepsis on admission - $\mathrm{n} .(\%)$ & - & $25(30)$ & \\
\hline Total ICU stay - median [IQR] & & $10[4-20]$ & \\
\hline ICU nonsurvivor - n. (\%) & - & $10(12)$ & \\
\hline
\end{tabular}

${ }^{1}$ Complicated surgery indicates patients suffering from complications after abdominal or pelvic surgery, pulmonary or esophageal surgery, or vascular surgery. The Acute Physiology and Chronic Health Evaluation II (APACHE II) score reflects severity of illness, with higher values indicating more severe illness, and can range from 0 to 71 (43). SE denotes standard error and IQR denotes interquartile range. 
Table 2: Multivariable linear regression analysis determining significant and independent associations between serum 3-T1AM and potential TH precursors

\begin{tabular}{|c|c|c|c|}
\hline Univariable analysis & $\begin{array}{c}\text { Estimated difference (95\% Cl) } \\
\text { for 3-T1AM (nmol/L) }\end{array}$ & $\mathbf{R}^{\mathbf{2}}$ & P-value \\
\hline TT4 (nmol/L) & $0.05(0.02-0.07)$ & 0.129 & $<0.0001$ \\
\hline TT3 (nmol/L) & $2.50(1.73-3.27)$ & 0.262 & $<0.0001$ \\
\hline rT3 (nmol/L) & $-0.45(-0.73--0.17)$ & 0.078 & 0.002 \\
\hline 3,5-T2 (nmol/L) & $-0.39(-0.69--0.09)$ & 0.055 & 0.01 \\
\hline & & & \\
\hline Multivariable analysis & $\begin{array}{c}\text { Estimated difference (95\% Cl) } \\
\text { for 3-T1AM (nmol/L) }\end{array}$ & $\mathbf{R}^{\mathbf{2}}$ & $\mathbf{P}$-value \\
\hline All & & 0.279 & $<0.0001$ \\
\hline TT4 (nmol/L) & $0.01(-0.03-0.04)$ & & 0.7 \\
\hline TT3 (nmol/L) & $2.22(0.91-3.53)$ & & 0.001 \\
\hline rT3 (nmol/L) & $-0.03(-0.37-0.30)$ & & 0.8 \\
\hline $3,5-T 2(n m o l / L)$ & $-0.17(-0.47-0.14)$ & & 0.2 \\
\hline
\end{tabular}


Table 3: Multivariable linear regression analysis determining significant and independent associations between serum 3,5-T2 and TH precursors

\begin{tabular}{|c|c|c|c|}
\hline Univariable analysis & $\begin{array}{c}\text { Estimated difference (95\% Cl) } \\
\text { for 3,5-T2 (nmol/L) }\end{array}$ & $\mathbf{R}^{\mathbf{2}}$ & P-value \\
\hline TT4 (nmol/L) & $-0.02(-0.03--0.01)$ & 0.062 & 0.006 \\
\hline TT3 (nmol/L) & $-0.72(-1.23--0.22)$ & 0.064 & 0.005 \\
\hline Multivariable analysis & $\begin{array}{c}\text { Estimated difference (95\% Cl) } \\
\text { for 3,5-T2 (nmol/L) }\end{array}$ & $\mathbf{R}^{\mathbf{2}}$ & P-value \\
\hline All & $-0.01(-0.03-0.01)$ & 0.074 & 0.01 \\
\hline TT4 (nmol/L) & $-0.44(-1.14-0.24)$ & & 0.2 \\
\hline TT3 (nmol/L) & & & 0.2 \\
\hline
\end{tabular}

Figure legends 


\section{Figure 1}
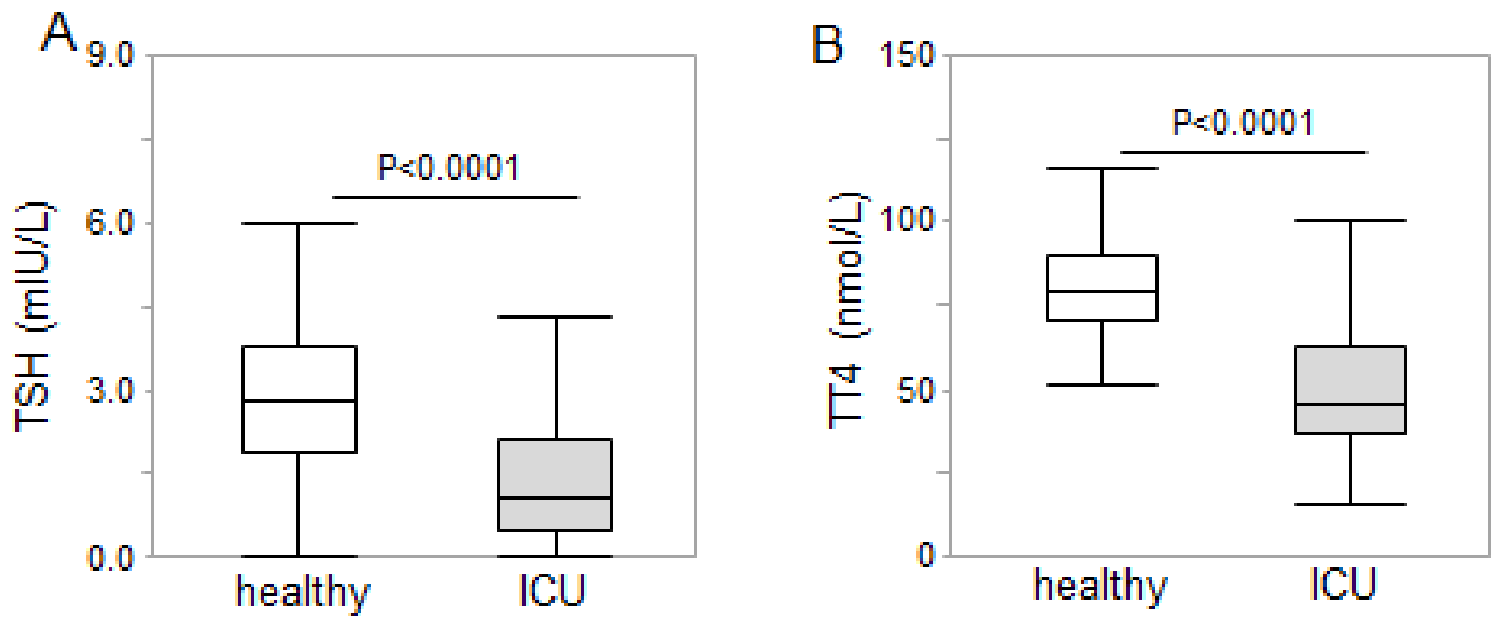

C

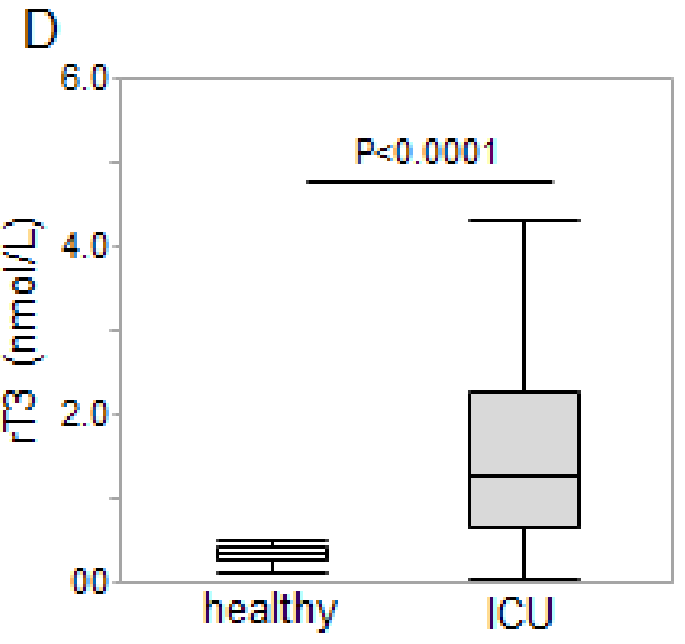

Figure 1: Comparison of serum thyroid hormone concentrations for healthy control subjects and ICU patients. The panels represent serum TSH (A), total T4 (B), total T3 (C), and rT3 (D) of healthy control subjects $(n=38)$ and critically ill patients $(n=83)$. Data are presented as medians and interquartile ranges. Healthy denotes healthy control subjects, ICU denotes intensive care unit patients. 
Figure 2
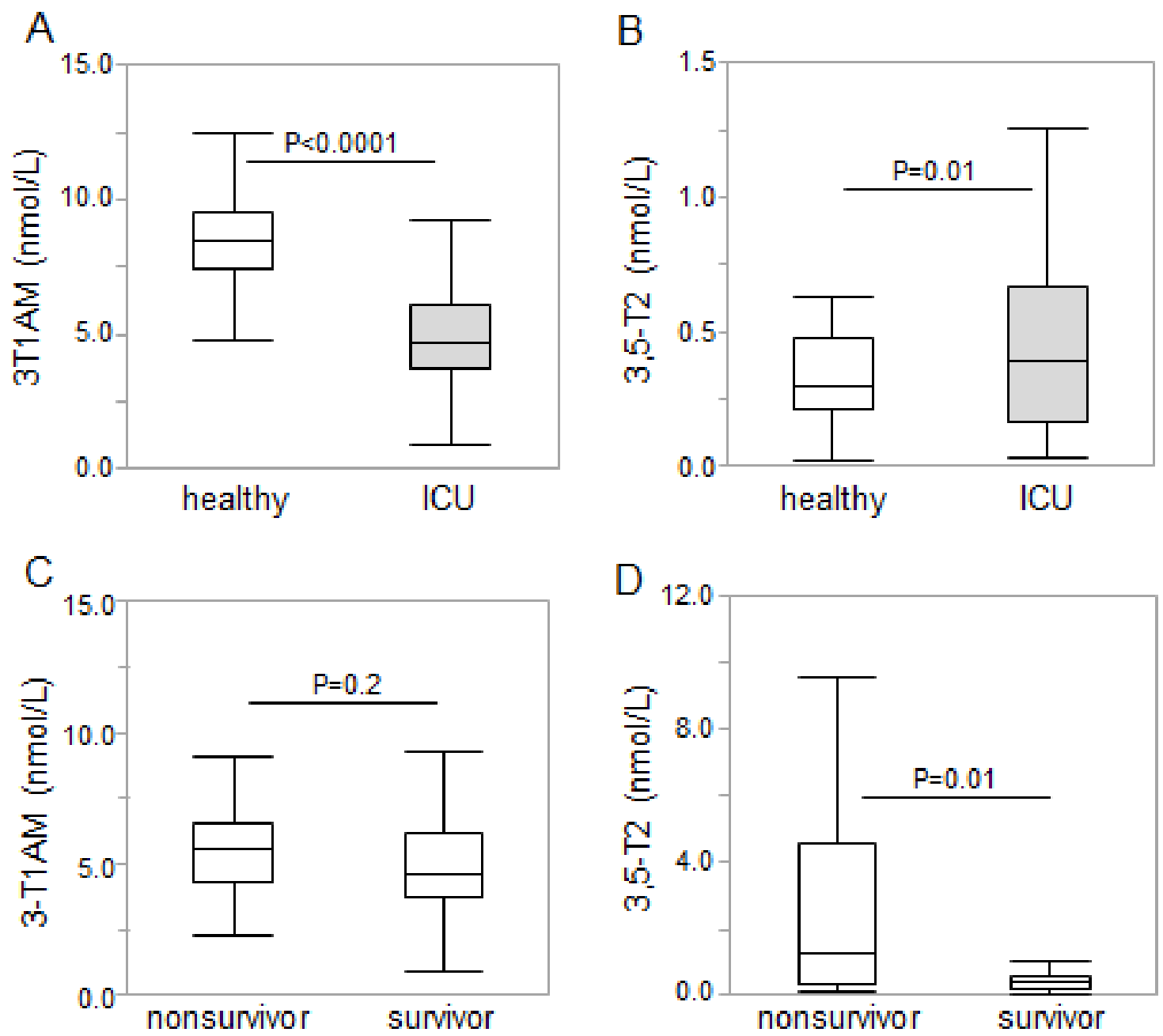

Figure 2: Comparison of serum 3-T1AM and 3,5-T2 in healthy control subjects and ICU patients. The upper panels represent serum 3-T1AM (A) and 3,5-T2 (B) of healthy controls $(n=38)$ and critically ill patients $(n=83)$. The lower panels represent serum 3-T1AM (C) and 3,5-T2 (D) of surviving $(n=73)$ and nonsurviving $(n=10)$ ICU patients. Data are presented as medians and interquartile ranges. Healthy denotes healthy control subjects, ICU denotes intensive care unit patients. 

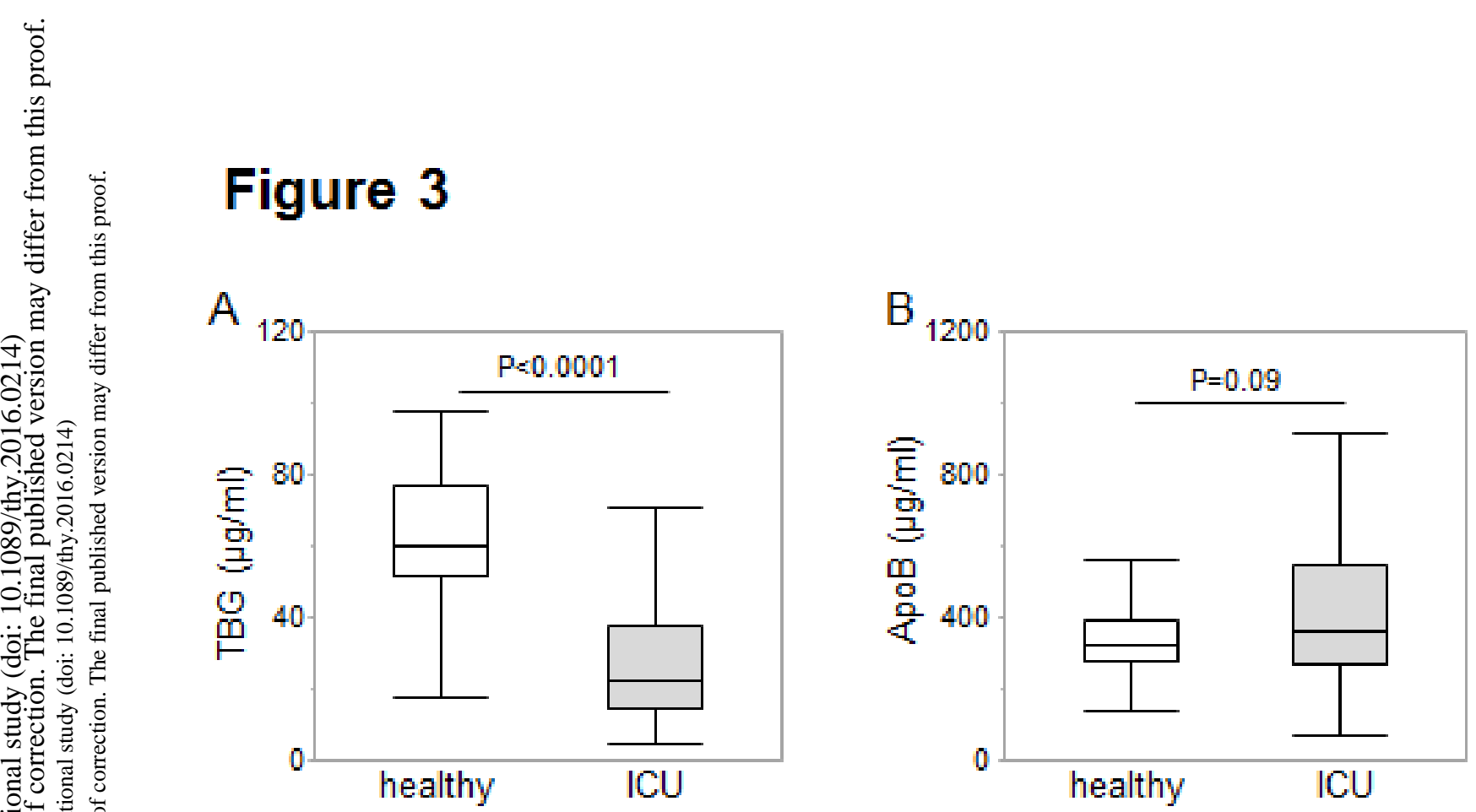

Figure 3: TH binding proteins. The panels represent serum TBG $(A)$ and $A p o B(B)$ of healthy control subjects $(n=38)$ and critically ill patients $(n=83)$. Data are presented as medians and interquartile ranges. Healthy denotes healthy control individuals, ICU denotes intensive care unit patients. 


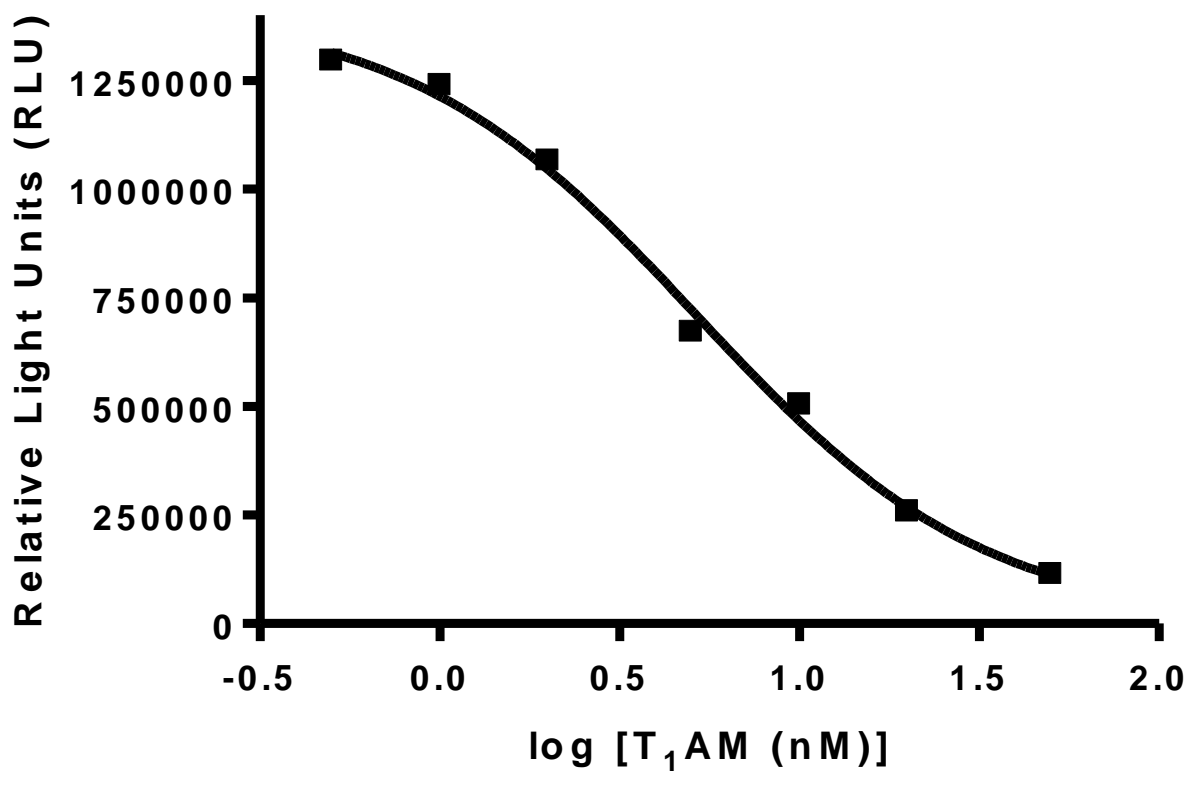

Supplemental figure 1: A representative standard calibrator curve of 3-T1AM. The in house developed monoclonal-antibody based chemiluminescence immunoassay is partly adapted from the previously described procedure (Hoefig et al, 2011). Plates are now coated with 3-T1AM-labelled BSA ( $50 \mu \mathrm{g}$ in $0.1 \mathrm{ml}$ per well; overnight at $4^{\circ} \mathrm{C}$ ), instead of coating with a polyclonal rabbit anti-mouse IgG (H\&L) as capture antibody, to minimize cross-reactivities between antibodies. The same previously used monoclonal antibody (mAb) for 3-T1AM is now biotinylated (10 $\mathrm{ng}$ in $0.05 \mathrm{ml}$ per well). Incubation time ( $1.5 \mathrm{~h}$ at $750 \mathrm{rpm}$ ) and serum volume $(25 \mu \mathrm{l}$ per determination) remained unchanged. High concentration serum samples may be diluted with 7\%BSA-PBST up to 1:4 with adequate recovery. Wells are automatically washed $(3 \times 0.35 \mathrm{ml} /$ well with wash-buffer $(10 \mathrm{mM}$ PBST, $0.05 \%$ Tween) and a 1:1000 dilution Streptavidin-Europium is added $(100 \mu \mathrm{l})$, incubated for $0.5 \mathrm{~h}$ with 750 $\mathrm{rpm}$ shaking, followed by automated wash steps $(6 \mathrm{x} 0.35 \mathrm{ml} /$ well wash-buffer). Then $200 \mu \mathrm{l}$ enhancement solution are added per well, further incubated for $10 \mathrm{~min}$ at $750 \mathrm{rpm}$ shaking and Relative Light Units (RLU) are recorded using a commercial plate reader. The modified 3-T1AM assay is characterized by a limit of detection below $1 \mathrm{nM}(0.93 \mathrm{nM})$, an accuracy of $115.5 \pm 12.0 \%$. The cross-reactivity with $3,5-\mathrm{T} 2 \mathrm{AM}$ is $12.4 \%$, with $3-\mathrm{T} 1 \mathrm{Ac} 5.1 \%$. Intra- $(<12.8 \%)$ and inter -assay variation $(<11.5 \%)$ were low.

Hoefig CS, Kohrle J, Brabant G, Dixit K, Yap B, Strasburger CJ, et al. Evidence for extrathyroidal formation of 3-iodothyronamine in humans as provided by a novel monoclonal antibody-based chemiluminescent serum immunoassay. J Clin Endocrinol Metab. 2011;96(6):1864-72 